\title{
Mitral and tricuspid valve repair and growth in unbalanced atrial ventricular canal defects
}

\author{
John E. Foker, MD, PhD, ${ }^{a}$ James M. Berry, RDMS, ${ }^{b}$ Brian A. Harvey, BA, ${ }^{a}$ and Lee A. Pyles, MD $^{b}$
}

Objective: Congenital mitral and tricuspid valve abnormalities in unbalanced atrioventricular canal defects are complex. We designed procedures to both repair and induce growth of hypoplastic atrioventricular valves and ventricles to achieve 2-ventricle repairs. Midterm data were assessed for reliability of catch-up growth, resulting quality of atrioventricular valves, and adequacy of 2-ventricle repairs.

Methods: The 24 consecutive infants (14 female and 10 male) with unbalanced atrioventricular canal defects had significant hypoplasia of 1 atrioventricular valve and/or ventricle (an echocardiography-derived $z$ value of $\leq-3.0$ standard errors of the mean below expected). Operative approaches included the following: (1) Staged repair was performed, with complete valve repair, partial closure of the atrial septal, and ventricular septal defects, and (usually) pulmonary artery banding. After adequate growth, repair was completed. A vestigial mitral valve (4-7 mm) in 3 patients led to partitioning the large tricuspid valve, creating a second mitral valve. (2) Repair with a shift in atrioventricular valve partitioning was performed to increase hypoplastic atrioventricular valve size. (3) Repair with snared atrial septal defects and ventricular septal defect was performed to allow intracardiac shunting. The hypoplastic atrioventricular valves and hypoplastic ventricles were reassessed on local follow-up (5-15 years).

\begin{abstract}
Results: The initial $z$ scores were -2.8 to -7.4 for hypoplastic atrioventricular valves and -1.0 to -7.5 for hypoplastic ventricles. Follow-up $z$ scores were -0.6 to -2.7 for hypoplastic atrioventricular valves and -2.0 to +1.8 for hypoplastic ventricles. Another 11 patients were also judged to be within normal limits. Three reoperations were for mitral valve regurgitation, and 1 reoperation was for mitral valve replacement. One patient died of central nervous system bleed just before extracorporeal membrane oxygenation weaning, and 2 patients died of late potassium overdose, for an $88 \%$ survival. Survivors are well with 2-ventricle repairs, and 15 of 19 patients are not taking cardiac medications.
\end{abstract}

Conclusions: Increasing atrioventricular valve flow reliably induced growth. Valve repair and growth achieved a 2-ventricle repair in all patients. (J Thorac Cardiovasc Surg 2012;143:S29-32)

Congenital mitral valve (MV) and tricuspid valve (TV) abnormalities take many forms, but those found in unbalanced atrioventricular canal (UAVC) defects are some of the most complex and difficult to treat. In addition to the structural valvar lesions, the difficulty is magnified by hypoplasia of the valve and ventricle, increasing the risk of an initial 2-ventricle repair. ${ }^{1}$ As a result, the majority of these infants are assigned to a single ventricle repair (SVR) track leading to the palliative Fontan procedure. A 2-ventricle repair may provide considerable long-term benefit but requires both

\footnotetext{
From the Divisions of Cardiothoracic Surgery ${ }^{\mathrm{a}}$ and Pediatric Cardiology, ${ }^{\mathrm{b}}$ University of Minnesota, Minneapolis, Minn.

Supported in part by the Robert and Sharon Kaster Endowment for Pediatric Cardiac Surgical Science.

Disclosures: John E. Foker, James M. Berry, Brian A. Harvey, and Lee A. Pyles have nothing to disclose with regard to commercial support.

Presented at The American Association for Thoracic Surgery Mitral Conclave, New York, New York, May 5-6, 2011

Received for publication May 1, 2011; revisions received Sept 21, 2011; accepted for publication Oct 20, 2011; available ahead of print Dec 8, 2011.

Address for reprints: John E. Foker, MD, PhD, Robert and Sharon Kaster Professor of Surgery, University of Minnesota, MMC 495, 420 Delaware St SE, Minneapolis, MN 55455 (E-mail: foker001@umn.edu).

$0022-5223 / \$ 36.00$

Copyright (c) 2012 by The American Association for Thoracic Surgery doi:10.1016/j.jtcvs.2011.10.031
}

effective repair of the significant atrioventricular valve (AVV) abnormalities and catch-up growth of the hypoplastic structures. We previously showed that increased flow across the AVV will induce growth and convert the hypoplastic structures into an adequately sized ventricle in patients with UAVCs. ${ }^{2}$ As our series of these patients grew, however, more severe AVV abnormalities were encountered, increasing the importance of the valve repair.

The purpose of this study was to present the types of AVV repair used and provide follow-up data on both their effectiveness and the results of growth induction in our series of patients with UAVCs. For all patients, the goal has been to achieve satisfactory 2 -ventricle repairs, but this strategy requires that several questions be addressed. We provide midterm data on (1) the quality of the AVVs after repair and growth, (2) the reliability of catch-up growth of the hypoplastic structures, and (3) the adequacy of the resulting 2-ventricle repairs to begin to determine whether the benefits are being realized.

\section{MATERIALS AND METHODS}

From 1995 to 2005,24 consecutive infants (14 female and 10 male) were diagnosed with UAVC $(\mathrm{N}=21)$ or related subsets $(\mathrm{N}=3)$ because 


$$
\begin{aligned}
& \text { Abbreviations and Acronyms } \\
& \text { ASD }=\text { atrial septal defect } \\
& \text { AVV }=\text { atrioventricular valve } \\
& \text { HAVV }=\text { hypoplastic atrioventricular valve } \\
& \text { HV }=\text { hypoplastic ventricle } \\
& \text { MV }=\text { mitral valve } \\
& \text { SVR }=\text { single ventricle repair } \\
& \text { TV }=\text { tricuspid valve } \\
& \text { UAVC } \\
& \text { VSD }=\text { unbalanced atrioventricular canal }
\end{aligned}
$$

of significant hypoplasia of $1 \mathrm{AVV}$ (hypoplastic atrioventricular valve [HAVV]) or the associated ventricle (hypoplastic ventricle [HV]). Leftsided hypoplasia was present in 19 patients, and right heart hypoplasia was present in 5 patients.

Preoperative and follow-up evaluations of AVV dimensions and ventricular volumes were calculated from echocardiography-derived data; these parameters have been used to determine suitability for a 2-ventricle repair. $^{2-6}$ AVV size was determined by 2 axis diameters and echocardiography-based programs for area. Preoperative ventricular evaluations were done using biplane echocardiograms and the modified Simpson's rule for volume calculations. All results were indexed $\left(\mathrm{M}^{2}\right)$ and the $z$ values calculated using standard nomograms $(z=$ standard error of the mean from expected; a method of standardization widely accepted in pediatric cardiac evaluations). Hypoplasia was defined as an echocardiographyderived $z$ score of -3.0 or less for either the AVV or the ventricle.

All patients, by AVV or ventricular evaluation, met the usual criteria to be placed on the SVR track. Despite the hypoplasia, all patients underwent operations designed to correct the valve lesions and induce growth, with the goal of achieving a 2-ventricle repair.

Despite the considerable variety in the lesions, the operations were grouped into 3 categories depending on the methods used to repair the AVVs and correct the hypoplasia: (1) Staged growth procedures were performed to first generate the growth signal followed by a second operation to complete the 2-ventricle repair $(\mathrm{N}=10)$. (2) Repartitioning of the AVV was performed to augment the valve area when this was the only hypoplastic component $(\mathrm{N}=9)$. (3) An almost complete repair was performed, but residual atrial septal defects (ASDs) and ventricular septal defects (VSDs) were left to allow cardiac output to be maintained by shunting until growth corrected the hypoplasia $(\mathrm{N}=5)$.

Our standard balanced atrioventricular canal operation consisted of complete repair of the common AVV, Dacron patch closure of the VSD, and autologous pericardial patch closure of the primum ASD; however, significant modifications were required in these patients with UAVC.

\section{Staged Repair}

The AVV was repaired, the VSD was partially closed (if the left ventricle was hypoplastic), the primum ASD was closed by a patch, and a second ASD was created and snared to be restrictive (gradient of 4-5 $\mathrm{mm} \mathrm{Hg}$ adjusted off bypass) to increase flow across the AVV into the HV as described. ${ }^{2}$ For patients with hypoplastic left ventricles, augmentation of the cardiac output by the right ventricle through the VSD required a pulmonary artery band to maintain systemic pressures in that chamber. For hypoplastic right ventricles, the VSDs were closed and a restrictive ASD allowed right to left shunting to both maintain cardiac output and increase TV flow. When catch-up growth of the hypoplastic structures was achieved, the ASD and VSD were closed, and the pulmonary artery was debanded.

This group included 3 patients with a large TV and a distinctly separate vestigial MV. For these patients, the MV was too small to be adequate; consequently, the TV was divided by the VSD patch creating a second MV (Figure 1). This division proved successful and allowed an adequate cardiac output through the 2 MVs.

For 1 of these patients, the large TV had $3+$ regurgitation preoperatively, and this remained in the new mitral component after partitioning and a subsequent attempt at repair. The problem was a lack of chordae along 1 quadrant of the TV, and an MV replacement was required.

For all patients, the second stage was carried out when catch-up growth reversed the hypoplasia $(z= \pm 1.0)$.

\section{Valve Repartition}

On the basis of the annulus of the common AVV, standard septation of the common AVV into 2 components would produce significant AVV hypoplasia in one. The mitral component would be deficient in 7 patients, along with mild to moderate hypoplasia of the left ventricle. In 2 patients, the tricuspid component was deficient. The size of the other AVV component, however, allowed repartitioning of the common AVV by the VSD and ASD patches to shift the functional annulus and augment the HAVV component. Placement of the VSD patch just inside the chordal margin of the $\mathrm{TV}$, for example, maximized the mitral component. The remainder of the repair was carried out in standard fashion.

\section{Almost Complete Repair With Residual Intracardiac Shunting}

Despite the hypoplasia of an AVV or ventricle reaching a $z$ score of -3.0 or less, our assessment in these patients indicated a standard atrioventricular canal repair could be carried out if a residual ASD/VSD was left behind. The septal defects would allow sufficient intracardiac shunting to maintain cardiac output. When the hypoplastic structures caught up in size, the septal defects would be expected to close later.

\section{Follow-up Evaluation}

The difficulties in patients returning for comprehensive follow-up examinations meant that many follow-up evaluations were done locally. In many cases, biplane echocardiography examinations were not done; therefore, the ventricular volumes of patients were only judged to be within normal limits or not within normal limits on the basis of a single view.

\section{RESULTS}

The preoperative data, operations, additional HAVV repairs at initial operations, HAVV reoperations, and HV and HAVV sizes initially, after growth, and at follow-up are shown in Table 1.

The additional AVV repairs done at the time of the first intracardiac operation included 3 cases of creating a second MV and 3 valvotomies to repair stenotic AVVs.

The second operation in the staged repair group was performed 5 to 145 (average 89) days after the first. Most patients $(9 / 10)$ were discharged during this interval. In 1 patient, growth appeared adequate in 5 days, allowing reduction of the ASD and VSD to $2 \mathrm{~mm}$ each. Because the patients were discharged, scheduling follow-up evaluations were done at convenience, and the reoperation does not reflect when catch-up growth occurred. Growth was relatively rapid, and we believe the second repair could have been done earlier (within 40 days).

All patients had completed 2-ventricle repairs. Three patients required reoperation for AVV regurgitation, and 1 

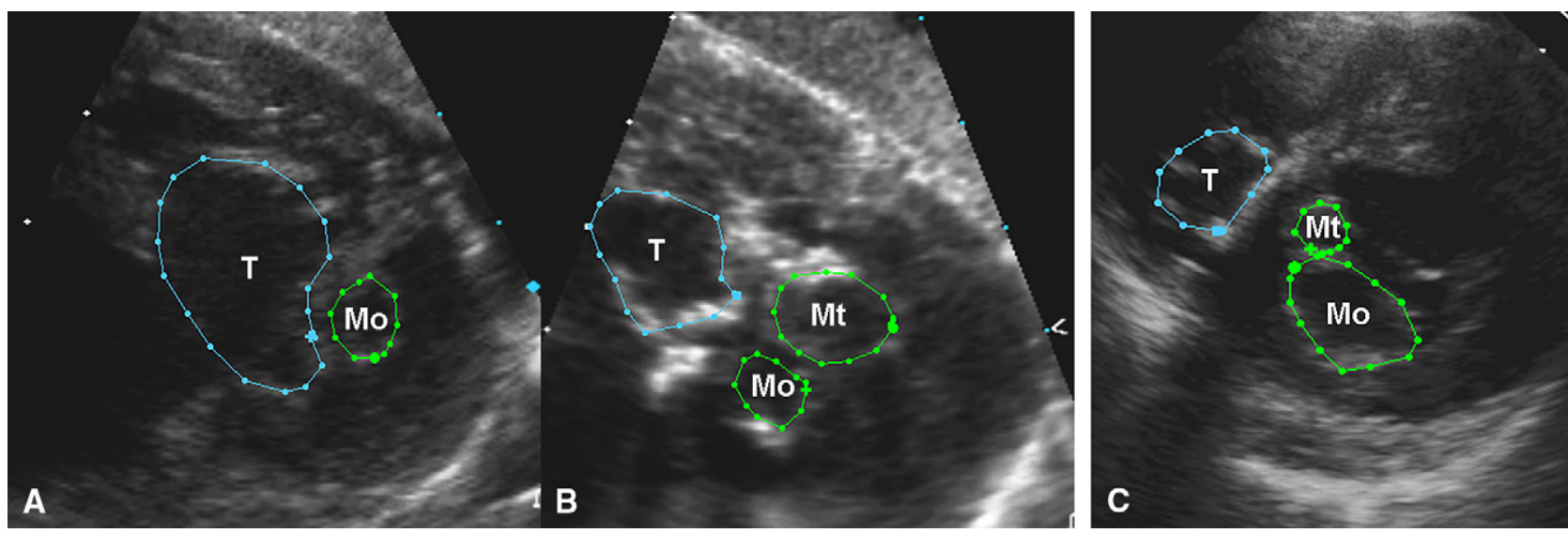

FIGURE 1. Creation of a second MV in a patient with UAVC and severe left AVV and ventricular hypoplasia with midterm follow-up. A, Preoperative (4 months of age) indexed areas: original MV $=0.27 \mathrm{~cm}^{2}, \mathrm{TV}=2.0 \mathrm{~cm}^{2}$. The preoperative TV z score was 0.8 , and the original MV was too small to calculate. Left ventricular volume $=1.3 \mathrm{~mL}, z=-7.5$. B, Postoperative ( 4 months of age) indexed areas after dividing the TV. Original MV $=0.28 \mathrm{~cm}^{2}$, mitral component from the TV $=0.68 \mathrm{~cm}^{2}, \mathrm{TV}=1.2 \mathrm{~cm}^{2} . \mathrm{C}$, Midterm (7-year) follow-up value areas showing catch-up growth of the original MV. Original $\mathrm{MV}=1.9 \mathrm{~cm}^{2}$, mitral component from the $\mathrm{TV}=0.36 \mathrm{~cm}^{2}, \mathrm{TV}=1.5 \mathrm{~cm}^{2}$, left ventricular volume $=77 \mathrm{~mL}, z=+0.2$. On follow-up, both the TV and original MV were within normal range. $M o$, Original MV; $M t$, mitral component from the TV; $T$, tricuspid valve.

patient who required MV replacement has been upsized to a larger valve. One patient underwent reoperation for an MV parachute deformity. Consequently, later problems with the HAVVs were relatively common $(\sim 20 \%)$; however, the valves were repaired with a satisfactory outcome. One patient with continuing left ventricular outflow obstruction required a Ross procedure.

All survivors have shown catch-up growth and corrected the hypoplasia (Table 1). The echocardiography studies revealed the remarkable growth potential of the hypoplastic structures (Figure 1). The vestigial MV with an indexed area of $0.27 \mathrm{~cm}^{2}$ and a $z$ score too small to be determined had grown to normal size (indexed area of $1.9 \mathrm{~cm}^{2}$ ) and function at the 7-year evaluation. The created MV grew but did not show catch-up growth, presumably because it was not needed or because of the effects of the operative TV septation.

There were 3 deaths in the series, including a central nervous system bleed just before weaning from extracorporeal membrane oxygenation in a patient whose repair was good and function had recovered. Two late deaths resulting from potassium overdose gave a midterm survival of $88 \%$.

On follow-up evaluation, the survivors all have 2-ventricle repairs and by report are "doing well," with 15 of 19 receiving no cardiac medications. Two patients did not have echocardiograms.

\section{DISCUSSION}

The MV and TV abnormalities along with associated ventricular hypoplasia in UAVC defects have posed considerable problems in repair and postoperative function. ${ }^{1}$ Because of the high mortality when significant valve or ventricular imbalance was present, much effort has gone into accurately determining what degree of hypoplasia would be tolerated after a complete repair. Once the septal defects are closed, no intracardiac shunting can take place to augment output and maintain stability. A complete repair in this setting will reveal the adequacy or inadequacy of the hypoplastic side.

TABLE 1. Atrioventricular valve and ventricle evaluation, operations, and follow-up data

\begin{tabular}{|c|c|c|c|c|c|c|c|c|c|}
\hline \multirow{2}{*}{$\begin{array}{c}\text { Initial HV } \\
\text { volumes }\end{array}$} & \multirow{2}{*}{$\begin{array}{c}\text { Initial } \\
\text { HAVV size }\end{array}$} & \multirow[b]{2}{*}{ Operations } & \multirow{2}{*}{$\begin{array}{c}\text { Additional HAVV } \\
\text { repairs at initial } \\
\text { operation }\end{array}$} & \multicolumn{2}{|c|}{$\begin{array}{c}\text { At second } \\
\text { stage of repair }\end{array}$} & \multirow{2}{*}{$\begin{array}{c}\text { HAVV } \\
\text { reoperations }\end{array}$} & \multirow[b]{2}{*}{ Follow-up } & \multirow{2}{*}{$\begin{array}{c}\text { Midterm } \\
\text { HV } z \text { scores }\end{array}$} & \multirow{2}{*}{$\begin{array}{c}\text { Midterm } \\
\text { HAVV size }\end{array}$} \\
\hline & & & & HV size & HAVV size & & & & \\
\hline \multirow[t]{2}{*}{$\begin{array}{l}1.5-4.7 \mathrm{~mL} \\
z=-3.6 \\
\quad \text { to }-7.5\end{array}$} & 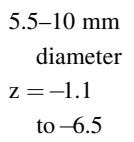 & Staged repair: 10 & $\begin{array}{l}\text { Creation of double } \\
\text { orifice MV: } 3 \\
\text { Repair of stenotic } \\
\text { AVV: } 3\end{array}$ & $\begin{array}{l}4.8-11.6 \mathrm{~mL} \\
\mathrm{z}=-0.5 \\
\quad \text { to }-1.4\end{array}$ & $\begin{array}{c}\text { 7-16 mm } \\
\text { diameter } \\
\mathrm{z}=+0.2 \\
\text { to }-1.3\end{array}$ & $\begin{array}{l}\text { Repair of } \\
\quad \text { regurgitation: } 3\end{array}$ & $5.4-15.0 \mathrm{y}$ & $\begin{array}{l}-1.0 \text { to }+2.0 \\
\text { and } 11 \text { within } \\
\text { normal } \\
\text { limits }\end{array}$ & $\begin{array}{c}-2.1 \text { to }+1.8 \\
\text { and } 8 \\
\text { normal } \\
\quad \text { limits }\end{array}$ \\
\hline & & $\begin{array}{l}\text { Partition of AVV to } \\
\text { correct HAVV: } 9 \\
\text { Complete repair } \\
\text { (with residual } \\
\text { ASD/VSD): } 5\end{array}$ & & & & $\begin{array}{l}\text { Repair of parachute } \\
\text { deformity: } 1 \\
\text { MV replacement: } 1\end{array}$ & & & \\
\hline
\end{tabular}


Consequently, efforts have been directed at determining with more precision the borderline between acceptable and unacceptable risks in proceeding with a complete 2-ventricle repair in patients with UAVC. Similar assessments have been carried out in other defects with ventricular hypoplasia. ${ }^{4}$ A variety of methods to determine ventricular size, and more recently HAVV area, have been used to define more accurately the borderline between adequate and inadequate. ${ }^{1-6}$ To standardize this preoperative assessment and make it reliable, the valve/ventricular sizes have been compared with standard nomograms, allowing $z$ scores to be calculated. Significant hypoplasia is acknowledged to be a $z$ score of -3.0 or less, which likely precludes a complete repair.

Significant abnormalities of the common AVV may be present to further complicate an atrioventricular canal repair. When mitral or tricuspid structural abnormalities are also present with the significant hypoplasia, a complete 2 -ventricle repair is hazardous. ${ }^{1,3-7}$ The mortality after repair increases steeply with the degree of hypoplasia; thus, SVR has been advocated whenever the valve or ventricular component has significant hypoplasia or deformity.

The focus has been placed almost entirely on deciding preoperatively which patients with an atrioventricular canal are too unbalanced and an SVR pathway should be chosen. This views the situation as fixed and completely discounts the potential for growth. Along with the results in this report, there is considerable evidence not only that substantial growth potential exists in these hypoplastic structures but also that the growth signal is known. ${ }^{2}$ Similar growth results have been obtained in lesions with hypoplastic right ventricles and TVs. ${ }^{8}$

The advantage of a satisfactory 2-ventricle repair in comparison with an SVR is becoming clearer as the effects of the latter become apparent. ${ }^{9}$ Although the SVR has had increasing short-term success, it can only be considered palliative. Furthermore, the patients with UAVC defects do not make good candidates for an SVR. When compared with patients with hypoplastic left heart syndrome, those with UAVCs have greater difficulties and a decreased survival after a Fontan operation. ${ }^{10}$ Abnormalities of the AVVs are of more consequence in SVRs. Consequently, it seems even more important that patients with UAVC defects eventually have a satisfactory 2 -ventricle repair.

\section{CONCLUSIONS}

Our series is relatively small; however, several conclusions can be drawn. Both the HAVVs and HVs have considerable growth potential, and in these patients, all hypoplastic structures showed adequate catch-up growth. The presence of intracardiac shunting during the time for catch-up growth allowed these patients to augment the output of the hypoplastic valves/ventricles and maintain stability. Additional operations on the HAVVs were required in $20 \%$ of patients, but they proved satisfactory. Overall, the resulting 2-ventricle repairs are satisfactory, and at least $88 \%$ do not have significant residual defects and are not receiving cardiac medications. The benefits over an SVR will likely increase with time.

\section{References}

1. Studer M, Blackstone EH, Kirklin JW, Pacifico AD, Soto B, Chung GKT, et al. Determinants of early and late results of repair of atrioventricular septal (canal) defects. J Thorac Cardiovasc Surg. 1982;84:523.

2. Foker JE, Berry JM, Steinberger J. Ventricular growth stimulation to achieve two-ventricle repair in unbalanced common atrioventricular canal. Prog Pediatr Cardiol. 1999;10:173-86.

3. Cohen MS, Jacobs ML, Weinberg PM, Rychik J. Morphometric analysis of unbalanced common atrioventricular canal using two-dimensional echocardiography. J Amer Coll Cardiol. 1996;28:1017-23.

4. Cohen MS, Rychik J. The small left ventricle: how small is too small for biventricular repair? Semin Thorac Cardiovasc Surg Pediatr Card Surg Annu. 1999;2: 189-202

5. Walter EMD, Ewert $\mathrm{P}$, Hetzer R, Hubler M, Alexi-Meskishvili V, Lange $\mathrm{P}$, et al. Biventricular repair in children with complete atrioventricular septal defect and a small left ventricle. Eur J Cardiothorac Surg. 2008;33:40-7.

6. Jegatheeswaran A, Pizarro C, Caldarone CA, Cohen MS, Baffa JM, Gremmels DB, et al. Echocardiographic definition and surgical decisionmaking in unbalanced atrioventricular septal defect: a congenital heart surgeons' society multi-institutional study. Circulation. 2010;122:S209-15.

7. Lim HG, Bacha EA, Marx GR, Marshall A, Flynn-Thompson F, Mayer JE, et al. Biventricular repair in patients with heterotaxy syndrome. J Thorac Cardiovasc Surg. 2009;137:371-9.e3.

8. Foker JE, Berry J, Setty SP, Harvey BA, Rivard AL, Gittenberger-de Groot AC, et al. Growth and function of hypoplastic right ventricles and tricuspid valves in infants with pulmonary atresia and intact ventricular septum. Prog Pediatr Cardiol. 2010;29:49-54.

9. Rychik J, Goldberg D, Dodds K. Long-term results and consequences of single ventricle palliation. Prog Pediatr Cardiol. 2010;29:19-24.

10. Owens GE, Gomez-Fifer C, Gelehrter S, Owens ST. Outcomes for patients with unbalanced atrioventricular septal defects. Pediatr Cardiol. 2009;30:431-5. 